\title{
Early Development of the Pineal Photoreceptors Prior to the Retinal Differentiation in the Embryonic Rainbow Trout, Oncorhynchus mykiss (Teleostei)*
}

\author{
Yuri OMURA and Mikio OGURI \\ Laboratory of Animal Information Biology, Nagoya University School of Agriculture, Nagoya, Japan
}

Received May 6, 1993

\begin{abstract}
Summary. The development of the pineal and retinal photoreceptors in the embryonic rainbow trout, Oncorhynchus mykiss was investigated by means of light and electron microscopy. The pineal photoreceptors endowed with photoreceptive outer segments and signaltransmitting synapses appeared first 15 days after fertilization, and well developed by 21 days. In contrast, the retinal photoreceptors appeared as late as 27 days after fertilization (1 day before hatching). This temporal disparity in photoreceptor development has been compared with the photoperiodic formation of otolith increments, which is initiated during an early developmental stage lacking retinal photoreception. It has been suggested that the early development of pineal photoreceptors may be involved in light-dark recognition, establishment of the diel and circadian rhythms, and entrainment to the environmental photoperiod in the embryonic rainbow trout.
\end{abstract}

For the survival of larval fish, establishment of the diel and circadian rhythms is essential during the early developmental stage. Compared to pelagic fish, salmonid fish usually have a very long embryonic period; their eyes differentiate slowly and mature just before visual feeding starts (see BLAXTER, 1975; ÖSTHOLM et al., 1987). In the rainbow trout, one species of salmonid fish, the photoperiodic formation of the otolith increments starts at the early embryonic stage lacking the retinal photoreception (MUGIYA, 1987). Therefore, lightdark recognition by some extraretinal photoreceptors, such as the pineal organ, must be established during the early embryonic stage of the trout. It is well known that the pineal organ acts as a photoendocrine transducer, which functions to synchronize the internal cycle with the environmental light cycles (see OKSCHE, 1986, 1989; also UNDERWOOD, 1989).

Early morphogenesis of the pineal photoreceptors has been found in several species of fish (three-spined stickleback: EKSTRÖM et al., 1983; Atlantic salmon: ÖsTHOLM et al., 1987; ayu and lefteye flounder: OMURA and OGURI, 1991). In a previous paper (OMURA and OGURI, 1991), we have demonstrated that the pineal photoreceptors develop earlier than their retinal counterparts in both the ayu Plecoglossus altivelis and the lefteye flounder Paralichthys olivaceus, despite great disparities in their incubation times and behavioral activities. Also, the initial appearance of photoreceptor specific proteins, such as rod-opsin, $\alpha$-transducin and S-antigen, has been demonstrated first in the pineal organ (VEEN et al., 1984; ÖSTHOLM et al., 1987, 1988). In the embryonic stage of the salmon, Salmo salar, such molecular differentiation occurs in the pineal photoreceptors 30 days before any specific protein appears in the retinal counterparts (ÖsTHOLM et al., 1987). In the ontogeny of Lampetra japonica, in addition, the pineal organ precedes the lateral eyes both structurally and functionally: during the larval period of several years, the vestigial eye bulbs are buried under the skin (TAMOTSU and MORITA, 1986).

In contrast, other different sequences of the photoreceptor development have been found in the pineal organ and retina of the ovoviviparous fish, Lebistes reticulatus (VIGH et al., 1986), and the hermaphroditic fish, Rivulus marmoratus (ALI et al., 1988): the pineal *This work was supported in part by Grant-in-Aid for Scientific Research (C) from the Ministry of Education, Science
and Culture, Japan (No. 03660189, 04660202). 
and retinal photoreceptors appear approximately at the same time. Also, in the embryonic chicken, there seems to be no temporal disparities in the morphogenesis between the pineal and retinal photoreceptors (see OMURA, 1977; MCLAUGHLIN, 1976; FUJISAWA, 1984). Moreover, the molecular mechanisms of the photoreceptor differentiation have been found to occur simultaneously in the retina and the pineal complex of the Zenopus leavis (KoRF et al., 1989). Thus, simultaneous differentiation of the pineal and retinal photoreceptors seems to be common to some vertebrates.

The present study demonstrates light and electron microscopic evidence that the pineal photoreceptors develop prior to the retinal differentiation in the embryonic rainbow trout, and discusses the coincidence of the appearance of pineal photoreceptors with the onset of the photoperiodic formation of the otolith increments.

\section{MATERIALS AND METHODS}

Fertilized eggs of the rainbow trout were obtained from Shiga Prefectural Samegai Trout Farm. They were incubated in a plastic basket hung in recirculating water tanks (temperature: $10-12^{\circ} \mathrm{C}$ ) under a $12 \mathrm{~L}$ 12D photoperiod $(06: 00-18: 00$ light and $18: 00-06: 00$ dark): light was supplied by cool fluorescence lamps (30-50 lux). Their retinal pigmentation first appeared 15 days after fertilization, and they hatched at 28 days.

Each batch of $6-10$ eggs at 15, 17, 21, 27 and 28 days after fertilization was selected and immersed in fixative ( $2 \%$ paraformaldehyde, $1 \%$ glutaraldehyde in $0.1 \mathrm{M}$ phosphate buffer, $\mathrm{pH}$ 7.3). The continued procedure of fixation and resine-embedding was essentially the same as described previously (OMURA and OGURI, 1991).

To demonstrate the membranous outer segments of the developing photoreceptors, we used, in addition to the toluidine-blue staining for light microscopy, the biotinylated WGA (wheat germ agglutinin) with $\mathrm{ABC}$ (avidin-biotin-peroxidase complex) method (Hsu and RAINE, 1982). Transversely-sectioned whole heads, $0.5-$ $1.0 \mu \mathrm{m}$ thick, were mounted onto gelatin-coated microscope slides. After removing the resin with sodium methoxide (MAYOR et al., 1961) and quenching of endogenous peroxidase, sections were preincubated in 1\% bovine serum albumin (BSA) in PBS for $20 \mathrm{~min}$ and subsequently rinsed in PBS without BSA. Sections were incubated with $200 \mu \mathrm{g} / \mathrm{ml}$ concentration of biotinylated WGA (VECTOR Lab.) solution in a humid chamber for $60 \mathrm{~min}$. Further PBS-rinsing was followed by incubation in an ABC solution (VECTASTAIN Elite ABC Kit), and diaminobenzidine reac- tion to visualize the peroxidase-labelled WGA-binding sites.

Ultrathin sections of the pineal region and the retina were stained with uranyl acetate and lead citrate and observed under a JEOL $100 \mathrm{CX}$ at $80 \mathrm{kV}$.

\section{RESULTS}

\section{Light microscopy of pineal development}

In normal embryonic stages of the rainbow trout, the first eye pigmentation appears 15 days after fertilization, by which time the pineal organ has also appeared. The principal cell layers of the retina are distinguishable 20 days after fertilization (cf. BALLARD, 1973). In this study, therefore, we closely examined the resine-embedded tissues of the pineal organ and retina from embryos at $15,17,21,27$ or 28 days (hatching day) after fertilization.

Fifteen days after fertilization, the pineal and parapineal organs are situated in median and slightly left positions, respectively. From the pineal epithelium, a few small bulbous protrusions swell into the pineal lumen. Seventeen days after fertilization, the pineal epithelial cells and the bulbous cytoplasmic protrusions are slightly increased in number (Fig. 1A).

By 21 days after fertilization, the bulbous cytoplasmic protrusions are largely increased in number, and are found along the luminal surface of the epithelium from the distal end to the proximal opening into the third ventricle. Large numbers are covered with toluidine blue-stained or WGA-binding cap-like structures, which have been recognized as lamellar membranes of the photoreceptor outer segment (Fig. 1BD, see also OMURA and OGURI, 1991).

Twenty-seven or 28 days after fertilization, the pineal organ is enlarged (more than $100 \mu \mathrm{m}$ in diameter) and the bulbous cytoplasmic protrusions are densely situated from the distal end to the proximal opening into the third ventricle.

\section{Light microscopy of the retinal development}

Fifteen days after fertilization, the outer layer of the retinal tissue is occupied by a simple flat pigment epithelium, which contains small numbers of pigment granules in its apical side. In contrast, the neural retina is still in mitosis and unstratified (cf. OMURA and OGURI, 1991). Twenty-one days after fertilization, the neural retina is conspicuously stratified with the principal cell layers: photoreceptors, bipolar cells and ganglion cells, and outer and inner plexiform layers (Fig. 1C, E). However, the outer and inner segments are undistinguishable between the well-pigmented 

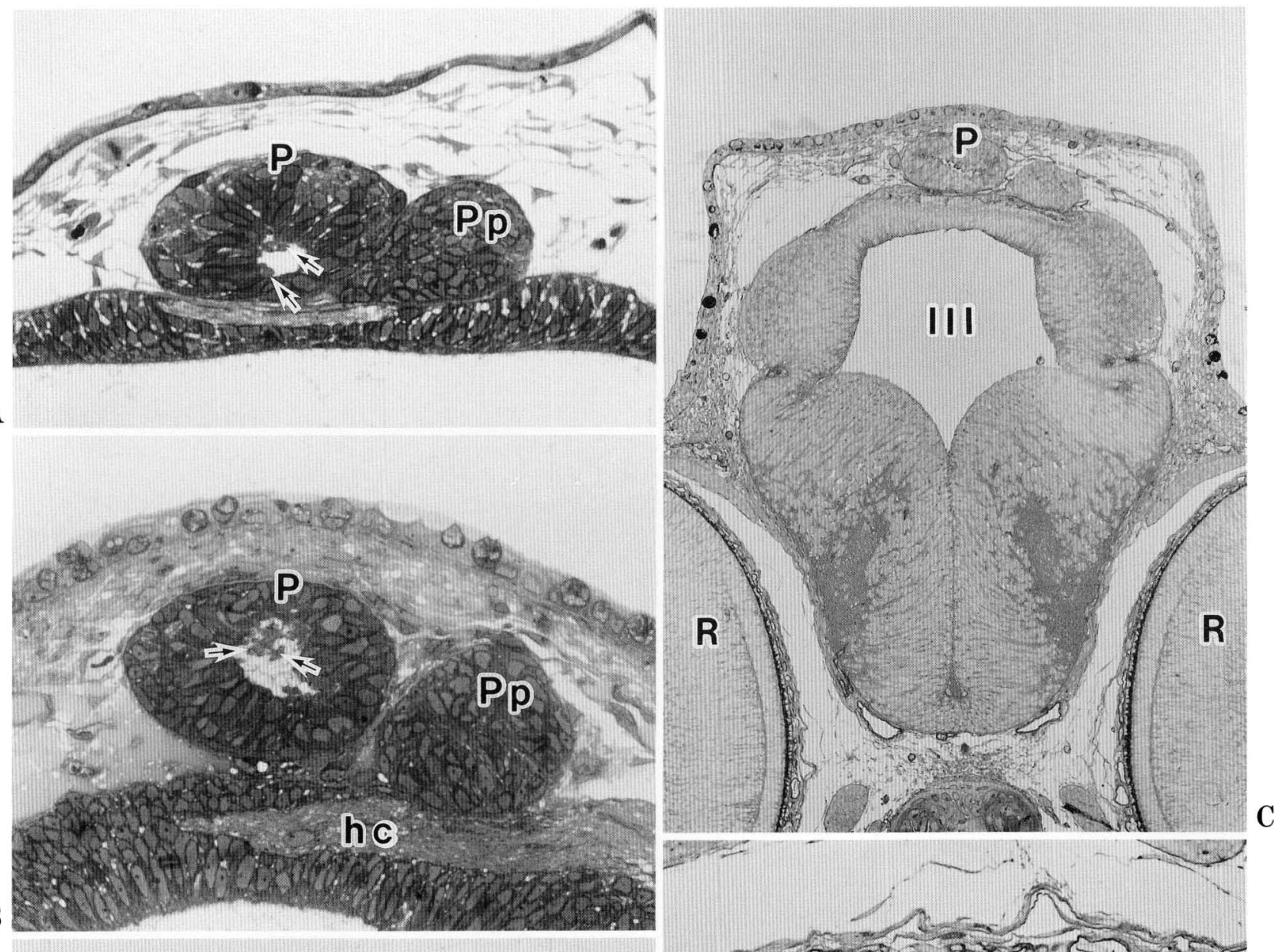

A
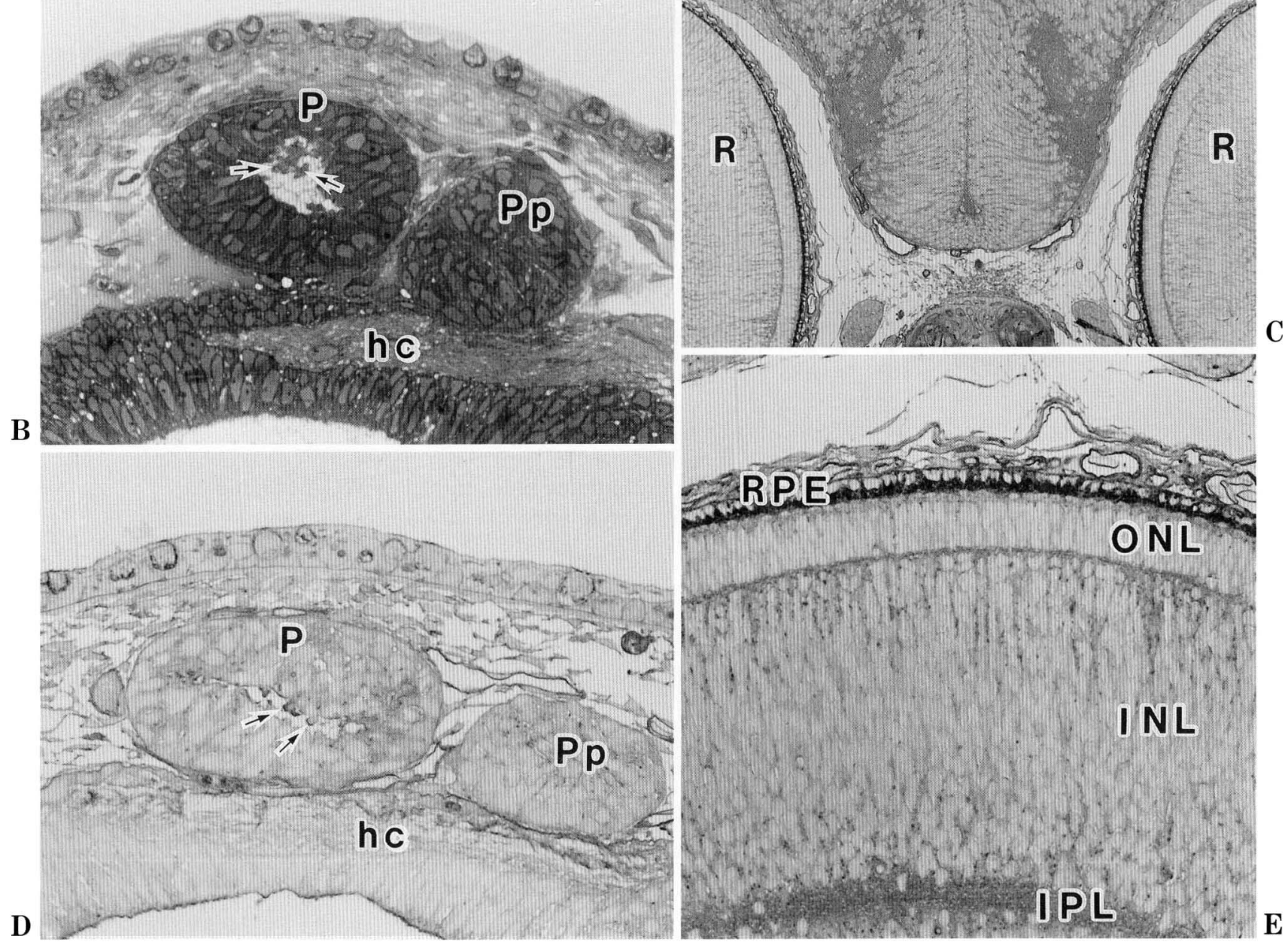

D

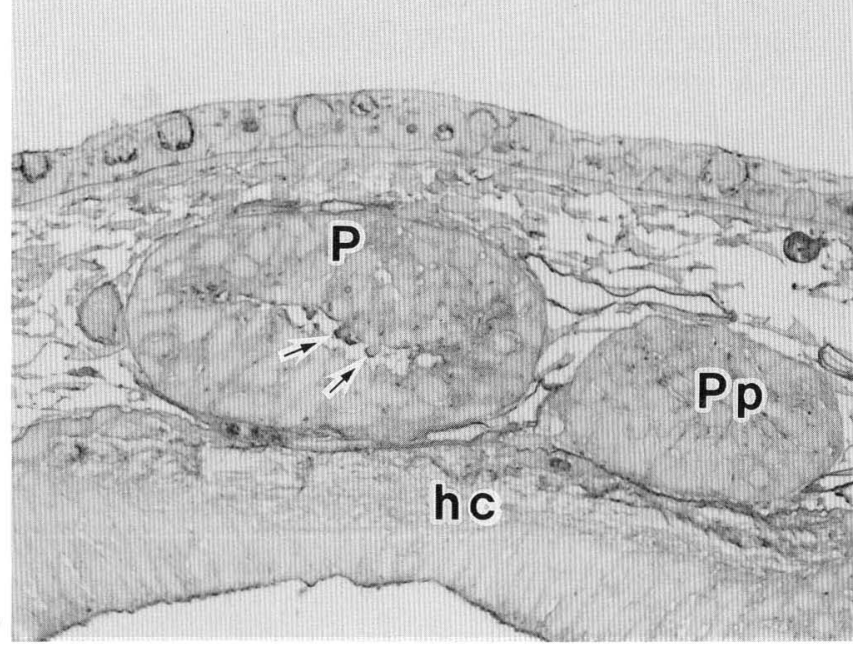

Fig. 1. Light micrographs of the developing pineal organ (A-D) and retina (C, E) of the embryonic rainbow trout, 17 days $(\mathbf{A}), 21$ days $(\mathbf{B}-\mathbf{E})$ after fertilization. The pineal organ $(P)$ and the retina $(R)$ of $\mathbf{C}$ are enlarged in $\mathbf{D}$ and $\mathbf{E}$, respectively. Small cytoplasmic protrusions (arrows) from the pineal epithelium are found in the pineal lumen $(\mathbf{A}, \mathbf{B}, \mathbf{D})$, while the outer and inner segment layers are indistinguishable between the pigment epithelium $(R P E)$ and the outer nuclear layer $(O N L)$ of the retina $(\mathbf{E})$. A, B: toluidin blue-staining, C, D, E: WGA-ABC reaction. $h c$ Habenular commissura, $I N L$ inner nuclear layer, $P p$ parapineal organ, $I I I$ third ventricle. $\mathrm{A}, \mathrm{B}, \mathrm{D}, \mathrm{E}: \times 360, \mathrm{C}: \times 120$ 

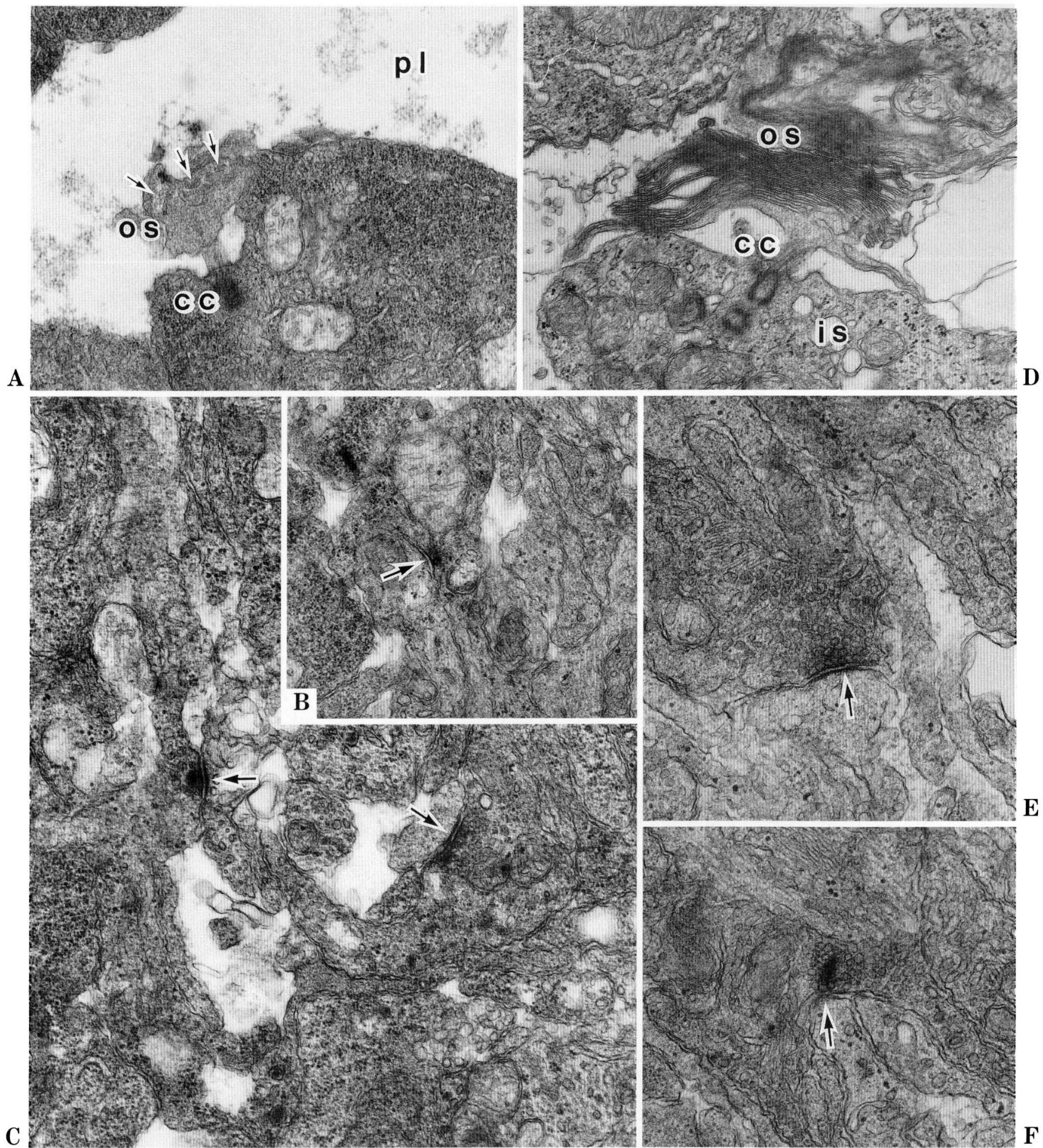

Fig. 2. Electron micrographs of the developing photoreceptor cells and neuropil from the pineal organ of the embryonic rainbow trout, 15 days $(\mathbf{A}, \mathbf{B}), 17$ days $(\mathbf{C})$, and 21 days $(\mathbf{D}-\mathbf{F})$ after fertilization. Small outer segment $(o s)$ protruding from the inner segment $(i s)$ into the lumen $(p l)$, and poorly differentiated synaptic connections (arrows) situated in the neuropil, are found in $\mathbf{A}, \mathbf{B}$ and $\mathbf{C}$, respectively. Moreover, well-developed outer segments possessing a number of lamellar membranes, and well-differentiated synaptic connections (arrows) including a synaptic ribbon and numerous synaptic vesicles are shown in $\mathbf{D}, \mathbf{E}$ and $\mathbf{F}$, respectively. A: $\times 15,000, \mathrm{~B}: \times 18,000$, $\mathrm{C}: \times 22,000, \mathrm{D}: \times 15,000, \mathrm{E}, \mathrm{F}: \times 29,000$ 
A

B
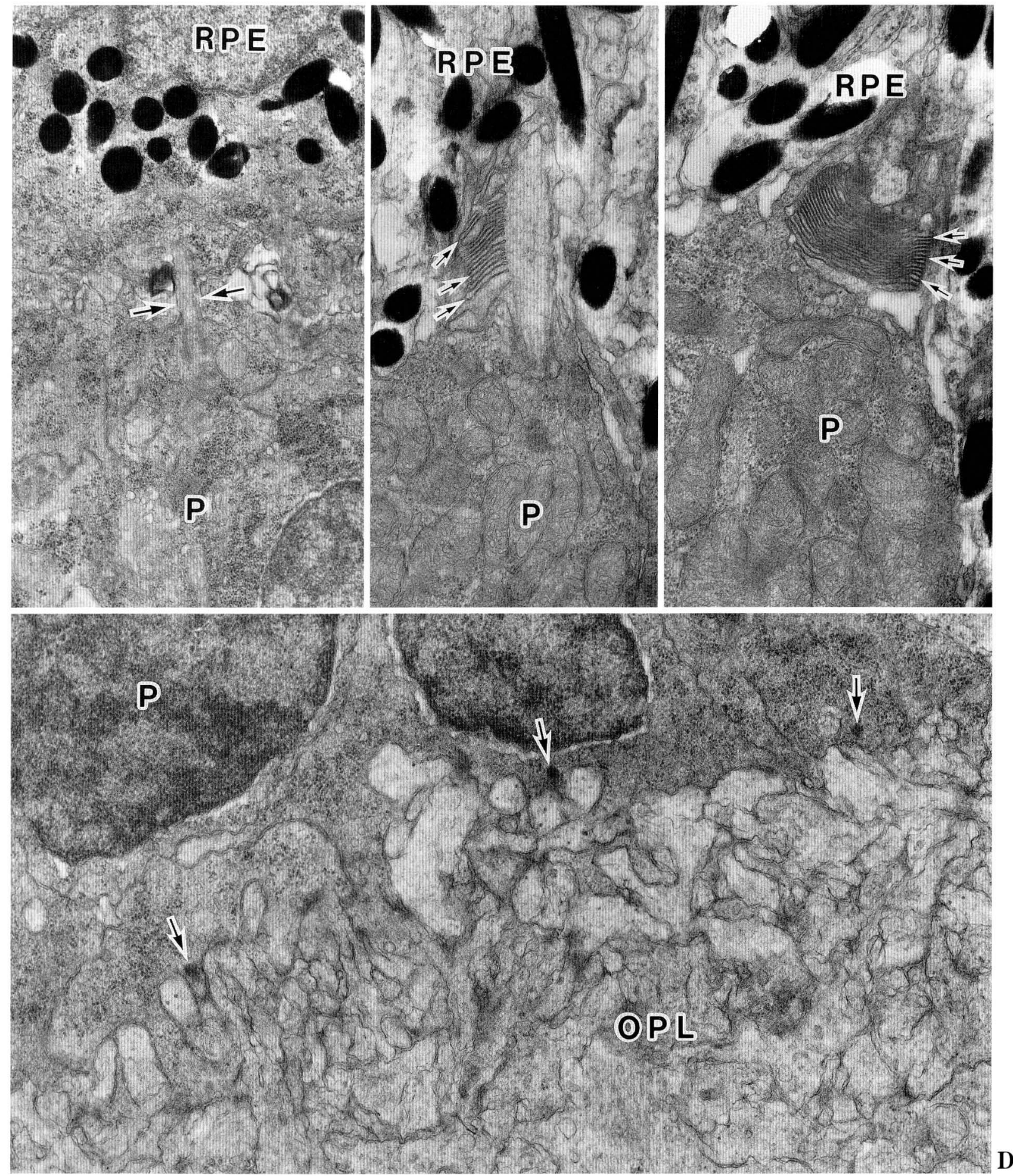

Fig. 3. Electron micrographs indicating the developing photoreceptor cells $(P)$ in the retinal epithelium of the eembryonic rainbow trout, 21 days (A) and 27 days (B-D) after fertilization. A. The supranuclear regions of primordial photoreceptor and pigment epithelial cells $(R P E)$ are rich in ribosomes and endoplasmic reticulum. Only a small cilium (arrows) protruding from the apical part of primordial photoreceptor cell is found. B and C. Developing outer segments possessing a number of lamellar membranes (arrows), which consist of infoldings of the plasma membrane. D. Developing outer plexiform layer $(O P L)$ including synaptic triads, which contain poorly developed synaptic ribbons (arrows) in the basal tips of photoreceptor cells. A: $\times 15,000, \mathrm{~B}, \mathrm{C}: \times 18,000$, D: $\times 20,000$ 
epithelial cell layer and the photoreceptor nuclear layer (Fig. 1E). At hatching, 28 days after fertilization, the pigment epithelium is densely pigmented and the neural retina is thoroughly stratified. Consequently, the outer and inner segment layers can be clearly identified (cf. OMURA and OGURI, 1991).

\section{Electron microscopy of the pineal development}

Fifteen days after fertilization, electron microscopic observation revealed the developing outer segment of the pineal photoreceptor (Fig. 2A). The outer segment protruding from the inner segment contains a small quantity of reticular and/or vesicular structures but none of the lamellar membranes in the apical side. Moreover, immature synaptic connections endowed with membranous presynaptic differentiation and synaptic vesicles are found in the developing neuropil (Fig. 2B).

Seventeen days after fertilization, outer segments endowed with the lamellar membranes, the receptive site for light stimulation, are found in the pineal epithelium. Sensory synapses endowed with synaptic ribbons and vesicles are also found between the basal ending of photoreceptor cell and the dendrite of secondary neurons in the developing neuropil (Fig. 2C).

Twenty-one days after fertilization, a number of well-developed outer segments of photoreceptor cells are found in the luminal space. These lamellar membranes are increased in number and size (Fig. 2D). Moreover, a large number of well-differentiated sensory synapses are localized in the pineal neuropil. Each presynaptic site is occupied by a number of synaptic vesicles and a developing synaptic ribbon (Fig. 2E, F).

\section{Electron microscopy of the retinal development}

Although the pigment granules had already appeared 15 days after fertilization in the pigment epithelial cells, the cellular stratification of the neural retina was first distinguishable 20 days after fertilization. Under the light microscope, the outer segment layer was first recognized at hatching, i.e., 28 days after fertilization. Accordingly, the ultrathin sections of the retinal specimens of 21 and 27 day-embryos were intensively examined.

Twenty-one days after fertilization, the supranuclear region of the pigment epithelial cells is occupied by a large number of pigment granules and densely crowded with ribosomes and endoplasmic reticulum. The apical region of the photoreceptor cell is rich in mitochondria, free and membrane-bound ribosomes and endoplasmic reticulum, but no conspicuous fea- tures of the outer segment are found except for a small cilium protruding from the apical side of the primordial photoreceptor cell (Fig. 3A).

Twenty-seven days after fertilization, developing outer segments endowed with a small or large number of lamellar membranes are found among the microvillous protrusions of the pigment epithelial cells filled with matured pigment granules (Fig. 3B, C). In the outer plexiform layer, in contrast, a poorly developed synaptic ribbon and a small number of synaptic vesicles appear at the basal end of the photoreceptor cell, which is invaded by nerve endings from the bipolar cells and the horizontal cells (Fig. $3 \mathrm{D})$.

\section{DISCUSSION}

The present study demonstrates that pineal photoreceptors endowed with photoreceptive outer segments and signal-transmitting sensory synapses appear as early as 15 days after fertilization, and are fully developed by 21 days. In contrast, the retinal photoreceptors appear as late as 27 days after fertilization ( 1 day before hatching). Thus, there is a great temporal disparity in photoreceptor development between the pineal organ and the retina of the rainbow trout.

As mentioned elsewhere (see OMURA and OGURI, 1991), the appearance of the membranous outer segment can be regarded as a morpholoical sign of the photoreceptive capacity to distinguish between light and dark. While it is difficult to compare the timing precisely, the lamellar membranes of outer segment appear almost in parallel when the photoreceptorspecific proteins occur in the pineal photoreceptors in the three-spined stickleback (see EKSTRÖM et al., 1983; VEEN et al., 1984; ÖsTHOLM et al., 1988). Recently, it has been demonstrated using developing Xenopus retina that opsin expression precedes any evidence of photoreceptor differentiation (SAHA and GRAINGER, 1993). Taking this knowledge into consideration, the pineal photoreceptors may initiate their photoreceptive capacity at an early stage of morphogenesis. In contrast, the developmental delay of retinal photoreceptors may depend on the absorption of the yolk and the initiation of feeding in larval fish. However, the cellular and molecular mechanisms regulating the photoreceptor differentiation in the pineal organ and the retina of the rainbow trout remain still to be elucidated.

According to KORF et al. (1989), the molecular differentiation involved in phototransduction processes commences simultaneously in the pineal orrgan and 
the retina of Xenopus laevis. Also in the chicken, morphological differentiation seems to occur almost simultaneously between the pineal and the retinal photoreceptors (see OMURA, 1977; MCLAUGHLIN, 1976; FuJISAWA, 1984). Thus, simultaneous differentiation in both photoreceptors seems to be a common event in some vertebrates. As mentioned above, similar developmental sequences have been found also in the pineal and retinal photoreceptors of ovoviviparous and hermaphroditic fish (VIGH et al., 1986; AlI et al., 1988).

In addition to the well-developed outer segments, the appearance of well-differentiated synaptic contacts in the developing photoreceptors seems to be solid evidence for the capability of propagating photic stimulation towards the brain. While the ontogenetic development of the pineal photoreceptors has been well described, only a few mentions of their synaptogenesis have been made because of the difficulty in detecting it (see OMURA and OGURI, 1971; EKSTRÖM et al., 1983; AlI et al., 1988). The present study revealed that, in the rainbow trout, the photoreceptor synaptogenesis occurs mostly in parallel with the development of the outer segment in the pineal neuropil and in the retinal outer plexiform layer, respectively. These findings are supported also by immunocytochemical studies performed using antibodies against the neurotransmitters and their synthesizing enzymes in the pineal organ and the retina of the three-spined stickleback (see ÖsTHOLM et al., 1988).

On the other hand, age determination of the fieldcaptured fish rests on the assumption that otolith increments are formed daily (see PANNELlA, 1971; JONES, 1986). According to MUGIYA (1987), the photoperiod works as a potential entrainer for the rhythmic formation of otolith increments in the embryonic and larval rainbow trout. At hatching, 14 otolith increments are counted in those specimens kept under $24 \mathrm{~h}$ photoperiod (e.g., 12L-12D). This corresponds to the number of days elapsing from the initiation of eye pigmentation. In normal embryonic stages, as mentioned above, the first eye pigmentation occurs 15 days after fertilization, when the pineal photoreceptors first appear and the daily formation of otolith increments starts. Thus, there is good accordance of the first appearance of pineal photoreceptors with the initial formation of otolith increments in the rainbow trout.

Consequently, it may be that the pineal organ is involved in the initiation and oscillation of the daily formation of otolith increments during the early developmental period of the rainbow trout lacking the retinal photoreception. However, it may be also possible that the extraretinal and extrapineal photoreceptors (e.g., otolith itself? hypothalamic photoreceptor systems? enzyme/substrate complexes exhibiting light-dependent changes?) are involved in oscillation of the photoperiodic formation of the otolith increments.

There is increasing evidence indicating that the pineal organ of the rainbow trout possesses a primary "photoneuroendocrine" capacity (see OKSCHE, 1986, 1989): evidence has been provided by electrophysiological (MORITA, 1966; HANYU and NIWA, 1970; TABATA et al., 1975; MEISSL et al., 1990), morphological (HAFEEZ and ZERIHUN, 1974; KORF, 1974; OMURA, 1979; OMURA and ALI, 1980; OMURA et al., 1985; EKSTRÖM and KORF, 1985), immunocytochemical (VIGH-TEICHMANN et al., 1983; EKSTRÖM et al., 1987; EKSTRÖM and MEISSL, 1989), and biochemical (GERN et al., 1978; TABATA et al., 1985; GERN and GREENHOUSE, 1988) studies. According to photobehavioral studies (BOUJARD and LEATHERLAND, 1991), the rainbow trout shows a marked circadian rhythm of food demand synchronized with the diel light cycle. However, rhythmic synthesis of melatonin, usually higher at night and lower during the day (cf. GERN et al., 1978; FALCón et al., 1987; GERN and GREENHOUSE, 1988; KeZUKA et al., 1989; IIGO et al., 1991; ZACHMANN et al., 1991), has been undetectable in the superfused pineal organ of rainbow trout kept under continuous dark (GERN and GREENHOUSE, 1987; GERN, 1991), though the nycthermal rhythm of plasma melatonin persists even after pinealectomy (GERN et al., 1978).

In the Xenopus leavis (KoRF et al., 1990), it has been demonstrated that the molecular differentiation of phototransduction processes coincides with the onset of melatonin-dependent photoneuroendocrine regulation of color change mechanisms of dermal melanophores. In the present study, we have revealed that the pineal photoreceptors of the rainbow trout appear at the early embryonic stage, when the photoperiodic formation of the otolith increments is initiated. However, the question of whether such diel activity in the embryonic trout is mediated by light-dark dependent rhythmic synthesis of melatonin in the pineal organ still remains to be verified.

Acknowledgements. The authors thanks Dr. S. FUSHIKI, Siga Prefectural Samegai Trout Farm, for providing the fertilized eggs of the rainbow trout. They are also indebted to Mrs. KoGA for her excellent technical assistance. 


\section{REFERENCES}

Ali, M. A., A. Klyne, E. H. Park and S. H. Lee: Pineal and retinal photoreceptors in embryonic Rivulus mar. moratus Poey. Anat. Anz. (Jena) 167: 359-369 (1988).

BALLARD, W. W.: Normal embryonic stages for salmonid fishes, based on Salmo gairdneri Richardson and Salvelinus fontinalis (Mitchill). J. Exp. Zool. 184: 7-26 (1973).

BLAXTER, J. H. S.: The eyes of larval fish. In: (ed. by) M. A. Ali: Vision in fishes. Plenum, New York, 1975 (p. 427-443).

Boujard, T. and J. F. LeatherLand: Circadian rhythms of food intake in fishes: the case of Hoplosternum littorale and Oncorhynchus mykiss (Abstract). In: NATOAdvanced Study Institute on "Rhythms in fishes". Lennoxville, Que., Canada, 1991 (p. 2-3).

Eкström, P. and H.-W. KoRF: Pineal neurons projecting to the brain of the rainbow trout, Salmo gairdneri Richardson (Teleostei). In-vitro retrograde filling with horseradish peroxidase. Cell Tiss. Res. 240: 693-700 (1985).

Ekström, P. and H. Meissl: Signal processing in a simple vertebrate photoreceptor system: the teleost pineal organ. Physiol. Bohemoslov. 38: 311-326 (1989).

EKström, P., B. Borg and T. VAN VeEN: Ontogenetic development of the pineal organ, parapineal organ, and retina of the three-spined stickleback, Gasterosteus aculeatus L. (Teleostei). Development of photoreceptors. Cell Tiss. Res. 233: 593-609 (1983).

Ekström, P., R. G. Foster, H.-W. KorF and J. J. Schalken: Antibodies against retinal photoreceptorspecific proteins reveal axonal projections from the photosensory pineal organ in teleosts. J. Comp. Neurol. 265: 25-33 (1987).

Falcón, J., J. F. Guerlottê, P. Voisin and J. P. Collin : Rhythmic melatonin biosynthesis in a photoreceptive pineal organ: a study in the pike. Neuroendocrinology 45: 479-486 (1987).

Fujisawa, H.: Histogesis of the retina. In: (ed. by) E. YAMADA and H. HASHImoto: Human histology-Sensory organs (In Japanese). Asakura-Shoten, Tokyo, 1984 (p. 179-207).

GERN, W. A.: Melatonin rhythms in trout pineal organs (Abstract). In: NATO-Advanced Study Institute on "Rhythms in fishes". Lennoxville, Que., Canada, 1991 (p. 7).

Gern, W. A. and S. S. Greenhouse: Examination in vitro melatonin secretion from superfused trout (Salmo gairdneri) pineal organ maintained under diel illumination or continuous darkness. Gen. Comp. Endocrinol. 71: 163-174 (1988).

Gern, W. A., D. W. Owens and C. L. RALPH: Persistence of the nycthemeral rhythm of melatonin secretion in pinealectomized or optic tract-sectioned trout (Salmo gairdneri). J. Exp. Zool. 205: 371-376 (1978).

Hafeez, M. A. and L. Zerihun: Studies on central projections of the pineal nerve tract in rainbow trout,
Salmo gairdneri Richardson, using cobalt chloride iontophoresis. Cell Tiss. Res. 154: 485-510 (1974).

HANYU, I. and H. NiwA: Pineal photosensitivity in three teleosts, Salmo irideus, Plecoglossus altivelis and Mugil cephalus. Rev. Can. Biol. 29: 133-140 (1970).

Hsu, S. M. and L. RAINe: Versatility of biotin-labeled lectins and avidin-biotin-peroxidase complex for localization of carbohydrate in tissue sections. J. Histochem. Cytochem. 30: 157-161 (1982).

Iigo, M., H. Kezuka, K. Aida and I. Hanyu: Circadian rhythms of melatonin secretion from superfused goldfish (Carassius auratus) pineal gland in vitro. Gen. Comp. Endocrinol. 83: 152-158 (1991).

Jones, C.: Determining age of larval fish with the otolith increment technique. Fish. Bull. 84: 91-103 (1986).

KEZUKA, H., K. AIDA and I. HanYU: Melatonin secretion from goldfish pineal gland in organ culture. Gen. Comp. Endocrinol. 75: 217-221 (1989).

KoRF, H.-W.: Acetycholinesterase-positive neurons in the pineal and parapineal organs of the rainbow trout, Salmo gairdneri (with special reference to the pineal tract). Cell Tiss. Res. 155: 475-489 (1974).

KoRF, B., M. D. Rollag and H.-W. KoRF: Ontogenetic development of S-antigen-immunoreactions in retinal and pineal photoreceptors of Xenopus leavis in relation to the onset of melatonin-dependent color-change mechanisms. Cell Tiss. Res. 258: 319-329 (1989).

MAYOR, H. D., J. C. HAMpton and B. Rosario: A simple method for removing the resin from epoxy-embedded tissue. J. Biophys. Biochem. Cytol. 9: 909-910 (1961).

McLaughlin, B.: A fine structural and E-PTA study of photoreceptor synaptogenesis in the chick retina. J. Comp. Neurol. 170: 347-364 (1976).

Meissl, H., C. Martin and M. Tabata: Melatonin modulates the neural activity in the photosensory pineal organ of the trout: evidence for endocrine-neuronal interactions. J. Comp. Physiol. A 167: 641-648 (1990).

MoRITA, Y.: Entladungsmuster pinealer Neurone der Regenbogenforelle (Salmo irideus) bei Belichtung des Zwischenhirns. Pflugers Arch. 289: 155-167 (1966).

MugiYA, Y : Effects of photoperiods on the formation of otolith increments in the embryonic and larval rainbow trout Salmo gairdneri. Nippon Suisan Gakkaishi 53: 1979-1984 (1987).

OKsche, A.: Historical perspectives of photoneuroendocrine systems. In: (ed. by) P. J. O'BRIEN and D. C. KLEIN: Pineal and retinal relationships. Academic Press, Orlando, 1986. (p. 1-13).

- : Pineal complex - the 'third' or 'first' eye of vertebrates?: a conceptual analysis. Biomed. Res. 10, Suppl. 3: 187-194 (1989).

OMURA, Y.: Ultrastructure study of embryonic and posthatching development in the pineal organ of the chicken (brown leghorn, Gallus domesticus). Cell Tiss. Res. 183: 255-271 (1977).

- : Light and electron microscopic studies on the pineal tract of rainbow trout, Saimo gaerdneri. Rev. Can. Biol. 38: 105-118 (1979).

OmuRA, Y. and M. A. Ali: Responses of pineal photorecep- 
tors in the brook and rainbow trout. Cell Tiss. Res. 208: 111-122 (1980).

OMura, Y. and M. OGURI: The development and degeneration of the photoreceptor outer segment of the fish pineal organ. Bull. Jap. Soc. Sci. Fish. 37: 851-860 (1971). : Photoreceptor development in the pineal organ and the eye of Plecoglossus altivelis and Paralichthys olivaceus (Teleostei). Cell Tiss. Res. 266: 315-323 (1991)

OMURA, Y., H.-W. KoRF and A. OKSChe: Vascular permeability (problem of the blood-brain barrier) in the pineal organ of the rainbow trout, Salmo gairdneri. Cell Tiss. Res. 239: 599-610 (1985).

Östholm, T., E. BRÄNNÄS and T. van VeEN: The pineal organ is the first differented light receptor in the embryonic salmon, Salmo salar L. Cell Tiss. Res. 249: 641-646 (1987).

Östholm, T., P. Ekström, A. BruUn and T. van VeEn: Temporal disparity in pineal and retinal ontogeny. Devel. Brain Res. 42: 1-13 (1988).

Pannella, G.: Fish otoliths: daily growth layers and periodical patterns. Science 173: 1124-1127 (1971).

SAHA, M. S. and R. M. GraINGER: Early opsin expression in Xenopus embryos precedes photoreceptor differentiation. Mol. Brain Res. 17: 307-318 (1993).

Tabata, M., T. Suzuki and H. Niwa: Chromophores in the extraretinal photoreceptor (pineal organ) of teleosts. Brain Res. 338: 173-176 (1985).

Tabata, M., T. Tamura and H. Niwa: Origin of the slow potential in the pineal organ of the rainbow trout. Vision Res. 15: 737-740 (1975).

Tamotsu, S. and Y. Morita: Photoreception in pineal organs of larval and adult lampreys, Lampetra japonica. J. Comp. Physiol. A 159: 1-5 (1986).

UNDERWOOD, H.: The pineal and melatonin: Regulators of circadian function in lower vertebrates. Experientia 45: 914-922 (1989).
Veen, T. van, P. Ekström, L. Nyberg, B. Borg, I. Vigh-TeichmanN and B. Vigh: Serotonin and opsin immunoreactivities in the developing pineal organ of the three-spined stickleback, Gasterosteus aculeatus L. Cell Tiss. Res. 237: 559-564 (1984).

Vigh, B., I. Vigh-TeichmanN, I. Reinhard, A. Szel and T. VAN VEEN: Opsin immunoreactions in the developing and adult pineal organ. In: (ed. by) D. GUPTA and R. J. REITER: The pineal gland during development from fetus to adult. Croom Helm, London-Sydney, 1986 (p. $31-42)$.

Vigh-TeichmanN, I., H.-W. KorF, F. Nürnberger, A. OKSCHE, B. VIGH and R. OLSSON: Opsin-immunoreactive outer segments in the pineal and parapineal organs of the lamprey (Lampetra fluviatilis), the eel (Anguilla anguilla), and the rainbow trout (Salmo gairdneri). Cell Tiss Res. 230: 289-307 (1983).

Zachmann, A., S. C. M. KNiJfF, V. Bolliet and M. A. ALI: Effects of temperature cycles and photoperiod on rhythmic melatonin secretion from the pineal organ of a teleost (Catostomus commersoni) in vitro. Neuroendocrinol. Lett. 13: 325-330 (1991).

\author{
Dr. Yuri OMURA \\ Laboratory of Animal Information Biology \\ School of Agriculture, Nagoya University \\ Chikusa, Nagoya \\ 464-01 Japan \\ 大村 百 合 \\ 464-01 名古屋市千種区不老町 \\ 名古屋大学農学部 \\ 動物比較情報学講座
}

